Open Access

\title{
Cytoreduction and HIPEC in the treatment of "unconventional" secondary peritoneal carcinomatosis
}

Maurizio Cardi ${ }^{1,3^{*}}$, Paolo Sammartino ${ }^{1}$, Valentina Mingarelli ${ }^{1}$, Simone Sibio ${ }^{1}$, Fabio Accarpio ${ }^{1}$, Daniele Biacchi ${ }^{1}$, Daniela Musio ${ }^{2}$, Bianca Sollazzo ${ }^{1}$ and Angelo Di Giorgio ${ }^{1}$

\begin{abstract}
Background: Peritoneal metastasis (PM) is considered a terminal and incurable disease. In the last 30 years, cytoreductive surgery (CRS) and hyperthermic intraperitoneal chemotherapy (HIPEC) radically changed the therapeutic approach for these patients and is regarded as the standard of care for pseudomyxoma peritonei from appendiceal cancer and peritoneal mesotheliomas. Improved survival has also been reported in treating PM from ovarian, gastric, and colorectal cancers.

However, PM often seriously complicates the clinical course of patients with other primary digestive and non-digestive cancers. There is increasing literature evidence that helped to identify not only the primary tumors for which CRS and HIPEC showed a survival advantage but also the patients who may benefit form this treatment modality for the potential lethal complications.

Our goal is to report our experience with cytoreduction and HIPEC in patients with PM from rare or unusual primary tumors, discussing possible "unconventional" indications, outcome, and the peculiar issues related to each tumor.

Methods: From a series of 253 consecutive patients with a diagnosis of peritoneal carcinomatosis and treated by CRS and HIPEC, we selected only those with secondary peritoneal carcinomatosis from rare or unusual primary tumors, excluding pseudomyxoma peritonei, peritoneal mesotheliomas, ovarian, gastric, and colorectal cancers. Complications and adverse effects were graded from 0 to 5 according to the WHO Common Toxicity Criteria for Adverse Events (CTCAE). Survival was expressed as mean and median.
\end{abstract}

Results: We admitted and treated by CRS and HIPEC 28 patients with secondary peritoneal carcinomatosis from rare or unusual primary tumors. Morbidity and mortality rates were in line with those reported for similar procedures. Median survival for the study group was 56 months, and 5-year overall survival reached $40.3 \%$, with a difference between patients with no (CCO) and minimal (CC1) residual disease (52.3 vs. 25.7), not reaching statistical significance. Ten patients are alive disease-free, and eight are alive with disease.

Conclusions: Cytoreduction and HIPEC should not be excluded "a priori" for the treatment of peritoneal metastases from unconventional primary tumors. This combined therapeutic approach, performed in an experienced center, is safe and can provide a survival benefit over conventional palliative treatments.

Keywords: HIPEC, Cytoreduction, Peritoneal metastasis, Peritonectomy procedures

\footnotetext{
*Correspondence: maurizio.cardi@uniroma1.it

'UOC Tecnologie Chirurgiche e Day Surgery, Dipartimento di Chirurgia

"P. Valdoni", "Sapienza" Università di Roma, Rome, Italy

${ }^{3}$ Via Bolzano 32, 00198 Rome, Italy

Full list of author information is available at the end of the article
}

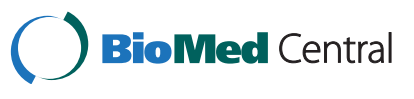

(c) 2015 Cardi et al. Open Access This article is distributed under the terms of the Creative Commons Attribution 4.0 International License (http://creativecommons.org/licenses/by/4.0/), which permits unrestricted use, distribution, and reproduction in any medium, provided you give appropriate credit to the original author(s) and the source, provide a link to the Creative Commons license, and indicate if changes were made. The Creative Commons Public Domain Dedication waiver (http://creativecommons.org/publicdomain/zero/1.0/) applies to the data made available in this article, unless otherwise stated. 


\section{Background}

Patients with peritoneal metastasis (PM) are typically considered as having a terminal and incurable disease and justifiably treated only by palliation with a very poor prognosis $[1,2]$. Although ovarian cancer is one of the most chemotherapy-sensitive solid tumors and one of the few for which the 5-year survival rate has improved, long-term survival in most women with locally advanced disease remains well below $20 \%$ [3-5]. Survival for PM from non-gynecologic malignancies is even worse. The EVOCAPE 1 multicenter study reports a median survival in patients treated with standard surgical and/or chemotherapy regimens of 6.5 and 5.2 months, respectively, in patients with primary gastric and colorectal cancer [6].

Over the past two decades, a novel therapeutic approach has emerged, combining cytoreductive surgery (CRS), performed to treat all visible disease, and hyperthermic intraperitoneal chemotherapy (HIPEC) used to treat microscopic residual disease [7, 8]. This treatment radically changed the therapeutic approach for patients with peritoneal surface malignancies and is nowadays regarded as the standard of care for pseudomyxoma peritonei from appendiceal cancer and peritoneal mesotheliomas $[9,10]$. In the last two decades, many studies also reported with this combined approach improved survival for the treatment of peritoneal metastases from ovarian [11-13], gastric [14, 15], and colorectal cancers [16-18].

Peritoneal metastases often complicate also the clinical course of many patients with other primary digestive and non-digestive cancers $[19,20]$. Due to the rarity of these conditions, the design of randomized clinical trials of CRS and HIPEC in these patients is unlikely. However, PM is frequently long-term confined to the peritoneal cavity without distant metastases, and death typically occurs for intractable bowel obstruction, development of malignant ascites and mesentery retraction, that often make it impossible to perform even the limited palliative surgery like a simple ostomy. A regional approach seems therefore reasonable in selected patients. Some medical oncologists remain skeptical mostly because of the complexity of the treatment and the perceived high complication rate [21] and the need to treat the patients only in highly specialized centers [22], but despite skepticism, many are the reports of CRS and HIPEC in the treatment of PM in these patients. Expanding literature reports helped to identify not only the primary tumors for which CRS/HIPEC offers a clear survival advantage but also the patients with rare or unusual primary ("unconventional") cancers who may benefit from this treatment modality for the potential lethal complications and survival advantage [23-25].

Our goal is to report our single-institution experience with CRS and HIPEC in patients with PM from rare or unusual primary tumors, discussing possible indications, outcomes, and the peculiar issues related to each tumor, hoping to contribute to extend the actual knowledge on the treatment of PM by this combined treatment.

\section{Methods}

From the clinical records of a series of 253 consecutive patients admitted in our Institution from November 2000 to December 2013 with a diagnosis of peritoneal carcinomatosis from various primary tumors and treated by maximal cytoreduction and HIPEC, we considered for this study only the patients with a diagnosis of secondary peritoneal carcinomatosis from "unconventional" primary tumors. All patients with primary peritoneal carcinomatosis and with secondary peritoneal carcinomatosis from ovarian, gastric, colorectal, and peritoneal mucinous adenocarcinoma of the appendix (PMCA) were excluded.

All patients gave informed written consent and had a clear histologic diagnosis of peritoneal carcinomatosis. We included only patients with a performance status of 0-2 [26], adequate cardiac, renal, pulmonary and bone marrow function, and resectable disease. Exclusion criteria were extraperitoneal spread, other malignancies, unresectable disease, and severe associated medical conditions.

At laparotomy extent of peritoneal carcinomatosis (PC) was recorded using the peritoneal cancer index (PCI) [27]. Complete surgical cytoreduction was then carried out to resect all visible disease.

Completeness of cytoreduction (CC) was recorded as proposed by Sugarbaker [28].

At the end of the surgical procedure, HIPEC was given with the closed technique. Four drains were positioned and connected to a closed extraperitoneal sterile circuit in which 4 to $6 \mathrm{~L}$ of perfusate was circulated by a peristaltic pump at a flow rate of $500 \mathrm{~mL} / \mathrm{min}$. The circuit was heated using an external heat exchanger connected to a heating circuit (EXIPER, Euromedical Italy). HIPEC was given at a temperature of $42-43{ }^{\circ} \mathrm{C}$ for 60 min using various chemotherapeutic drugs according to the primary tumor (Table 1). At the end, the abdomen was washed with 3-4 $\mathrm{L}$ of sterile saline solution at $37{ }^{\circ} \mathrm{C}$.

Surgical complications and adverse effects were monitored and graded from 0 to 5 ( $0-$ No event; $1-$ Mild; 2-Moderate; 3-Severe; 4-Life-threatening; 5-Deathrelated) according to the World Health Organization Common Toxicity Criteria for Adverse Events (CTCAE) [29].

The medical oncologic staff planned systemic chemotherapy when deemed necessary. Patients were followed up every 3 months with clinical evaluation and serummarker monitoring. Imaging techniques were obtained if indicated by the patient's clinical presentation. 
Table 1 Patients clinical characteristics and survival

\begin{tabular}{|c|c|c|c|c|c|c|c|c|}
\hline PT & Age & Sex & Primary $\mathrm{T}$ & HIPEC & $\mathrm{PCl}$ & CC & $\mathrm{FU}$ & Surv \\
\hline 1 & 72 & M & Sarcoma & $\mathrm{OXAL}^{\mathrm{a}}$ & 20 & 1 & $\mathrm{DOD}^{\mathrm{c}}$ & 12 \\
\hline 2 & 77 & $\mathrm{~F}$ & Sarcoma & OXAL ${ }^{a}$ & 16 & 0 & AWD $^{d}$ & 11 \\
\hline 3 & 61 & M & Sarcoma & OXAL ${ }^{a}$ & 14 & 1 & $A W D^{d}$ & 9 \\
\hline 4 & 68 & $\mathrm{~F}$ & Small bowel & $\mathrm{CDDP}^{\mathrm{b}}$ & 26 & 0 & $\mathrm{ADF}^{\mathrm{e}}$ & 23 \\
\hline 5 & 51 & M & Small bowel & $C D D P^{b}$ & 15 & 0 & $\mathrm{AWD}^{\mathrm{d}}$ & 23 \\
\hline 6 & 59 & M & Small bowel & $\mathrm{CDDP}^{\mathrm{b}}$ & 20 & 1 & $A W D^{d}$ & 8 \\
\hline 7 & 46 & F & Small bowel & $\mathrm{CDDP}^{\mathrm{b}}$ & 7 & 0 & $A W D^{d}$ & 3 \\
\hline 8 & 67 & M & Pancreas & OXAL & 23 & 1 & $\mathrm{ADF}^{\mathrm{e}}$ & 5 \\
\hline 9 & 67 & M & Pancreas & $\mathrm{OXAL}^{c}$ & 22 & 2 & $A_{W}{ }^{d}$ & 4 \\
\hline 10 & 74 & $\mathrm{~F}$ & Pancreas & OXAL ${ }^{c}$ & 3 & 0 & $\mathrm{ADF}^{\mathrm{e}}$ & 8 \\
\hline 11 & 70 & $\mathrm{~F}$ & $\mathrm{GIST}^{f}$ & $\mathrm{CDDP}^{\mathrm{b}}$ & 6 & 0 & $\mathrm{ADF}^{\mathrm{e}}$ & 34 \\
\hline 12 & 53 & F & $\mathrm{GIST}^{f}$ & $\mathrm{CDDP}^{\mathrm{b}}$ & 12 & 0 & $\mathrm{ADF}^{\mathrm{e}}$ & 108 \\
\hline 13 & 73 & M & $\mathrm{GIST}^{\dagger}$ & $\mathrm{CDDP}^{\mathrm{b}}$ & 20 & 0 & $\mathrm{DOD}^{\mathrm{c}}$ & 38 \\
\hline 14 & 58 & $\mathrm{~F}$ & Breast IDC & CDDP ${ }^{b}$ & 15 & 0 & $\mathrm{ADF}^{\mathrm{e}}$ & 128 \\
\hline 15 & 54 & $\mathrm{~F}$ & Breast ILC ${ }^{\mathrm{h}}$ & $\mathrm{CDDP}^{\mathrm{b}}$ & 22 & 1 & $\mathrm{ADF}^{\mathrm{e}}$ & 74 \\
\hline 16 & 55 & F & Breast ILCh & $C D D P^{b}$ & 22 & 2 & $\mathrm{DOD}^{\mathrm{c}}$ & 56 \\
\hline 17 & 77 & $\mathrm{~F}$ & Breast IDC & $\mathrm{CDDP}^{\mathrm{b}}$ & 24 & 1 & $\mathrm{ADF}^{\mathrm{e}}$ & 45 \\
\hline 18 & 53 & $F$ & Breast IDC & CDDP ${ }^{b}$ & 18 & 0 & $\mathrm{ADF}^{\mathrm{e}}$ & 13 \\
\hline 19 & 60 & M & Bladder & $\mathrm{CDDP}^{\mathrm{b}}$ & 19 & 2 & $\mathrm{DOD}^{\mathrm{c}}$ & 9 \\
\hline 20 & 68 & F & Type II UPSC & $\mathrm{CDDP}^{\mathrm{b}}$ & 5 & 0 & $\mathrm{DOD}^{\mathrm{c}}$ & 46 \\
\hline 21 & 56 & $\mathrm{~F}$ & Type II UPSC & CDDP ${ }^{b}$ & 6 & 0 & $\mathrm{DOD}^{\mathrm{c}}$ & 24 \\
\hline 22 & 64 & $\mathrm{~F}$ & Type II UPSC' & $\mathrm{CDDP}^{\mathrm{b}}$ & 23 & 0 & $A_{W}{ }^{d}$ & 12 \\
\hline 23 & 58 & $\mathrm{~F}$ & Type II UPSC & $\mathrm{CDDP}^{\mathrm{b}}$ & 17 & 0 & $\mathrm{AWD}^{\mathrm{d}}$ & 52 \\
\hline 24 & 61 & F & Type II UPSC & $C D D P^{b}$ & 9 & 0 & $\mathrm{ADF}^{\mathrm{e}}$ & 95 \\
\hline 25 & 67 & $\mathrm{~F}$ & Type II UPSC ${ }^{\mathrm{i}}$ & $\mathrm{CDDP}^{\mathrm{b}}$ & 30 & 1 & $\mathrm{DOD}^{\mathrm{c}}$ & 15 \\
\hline 26 & 59 & F & Type II UPSC ${ }^{\mathrm{i}}$ & $\mathrm{CDDP}^{\mathrm{b}}$ & 29 & 1 & $\mathrm{DOD}^{\mathrm{c}}$ & 15 \\
\hline 27 & 65 & $\mathrm{~F}$ & Type II UPSC ${ }^{\mathrm{i}}$ & $\mathrm{CDDP}^{\mathrm{b}}$ & 19 & 0 & $\mathrm{DOD}^{\mathrm{c}}$ & 12 \\
\hline 28 & 51 & M & Lung & CDDP ${ }^{b}$ & 19 & 0 & $\mathrm{DOD}^{\mathrm{C}}$ & 7 \\
\hline $\begin{array}{l}\text { aOxa } \\
{ }^{\mathrm{b}} \mathrm{Cis} \\
{ }^{\circ} \mathrm{Die} \\
{ }^{\mathrm{d}} \mathrm{Ali} \\
{ }^{\mathrm{e}} \mathrm{Aliv} \\
\mathrm{f} \\
\mathrm{f} \text { Gas } \\
{ }^{\mathrm{g}} \text { Inv } \\
{ }^{\circ} \text { Inv }\end{array}$ & $\begin{array}{l}\text { liplatin } \\
\text { latin } \\
\text { of dise } \\
\text { e with d } \\
\text { e diseas } \\
\text { rointest } \\
\text { sive du } \\
\text { sive lob }\end{array}$ & $\begin{array}{l}\text { ase } \\
\text { isease } \\
\text { e-free } \\
\text { nal strc } \\
\text { tal car } \\
\text { ular ca }\end{array}$ & $\begin{array}{l}\text { mal tumor } \\
\text { inoma } \\
\text { cinoma } \\
\text { lary serous }\end{array}$ & & & & & \\
\hline
\end{tabular}

Survival was expressed as mean and median. The Kaplan-Meier method was used to construct survival curves, and log-rank test was used to assess the significance of the differences (cutoff values $p<0.05$ ).

\section{Results}

A total of 28 patients with secondary peritoneal carcinomatosis from unconventional primary tumors were admitted and treated by CRS and HIPEC in our Institution. The clinical characteristics and type of primary tumor are reported in Table 1. Mean PCI was 17.1. Twenty-five patients (89\%) had an optimal cytoreduction (17 CC0 and 8 CC1) while three $(10.7 \%)$ had CC2 residual disease. Peritonectomy procedures lasted a mean of $475 \mathrm{~min}$ (range 300-780) including $60 \mathrm{~min}$ of HIPEC. All operations led to major blood loss (mean $1350 \mathrm{~mL}$, range 500-3900) and required intraoperative blood (mean 4 units, range 2-8) and plasma (mean 6 units, range 2-10) transfusions.

Most patients (16, $57.1 \%$ ) had an uneventful recovery. The only HIPEC-related adverse event was a grade 1 renal cisplatin toxicity reversed by medical treatment.

Grade 1/2 complications developed in six (21.4\%), grade 3 in two $(7.1 \%)$, and grade 4 in four (14.2\%) patients. Of the four patients with grade 4 complications, two underwent a second operation for fistulas (one colonic and one small bowel) caused by the surgical maneuvers needed to ablate bowel implants, one for postoperative bleeding, and one for an abdominal eventration. Mean postoperative stay was 19.2 days (range 8-71).

Median survival for the study group was 56 months, and 5-year overall survival reached $40.3 \%$, with a difference between $\mathrm{CC} 0$ and $\mathrm{CC} 1$ patients (52.3 vs. 25.7), not reaching statistical significance (Fig. 1). Ten patients are alive disease-free, and eight are alive with disease (Table 1).

\section{Discussion}

Management of peritoneal metastases from breast cancer Peritoneal carcinomatosis from breast cancer $(\mathrm{BC})$ is rare but carries high morbidity and mortality [30-32], and no clear guidelines are available regarding the role of CRS with or without HIPEC for those patients [33, 34]. Literature reports are sporadic and only Gusani, one patient in 2008 [1], and Glehen, two patients in 2010 [15], reported PM from BC treated by CRS and HIPEC. Our study

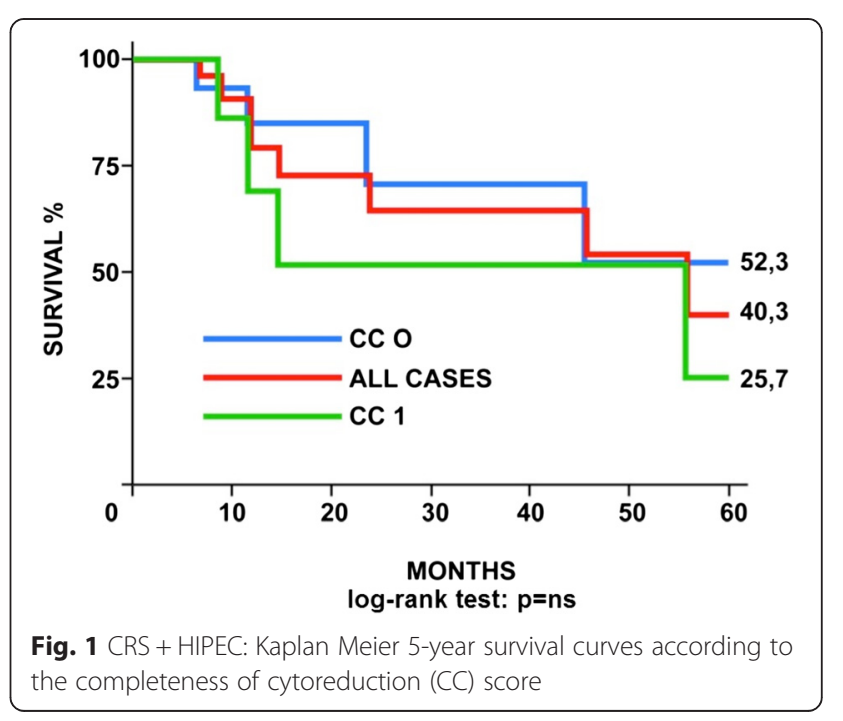


provides previously unavailable information on the treatment of women with PM from BC showing that once the correct diagnosis has been established [30], these patients can benefit from treatment and possibly argues against previous reports describing a poor prognosis. In our patients, a median 18 years (range 10-30) elapsed after BC was diagnosed and peritoneal carcinomatosis developed and accords with previous reports describing breast carcinoma as one of the most slowly growing solid tumors given that metastases may appear even decades after the initial diagnosis [34, 35]. Of the five patients treated, four achieved long-term survival, one surviving even for 10 years with good QOL.

Although CRS and HIPEC cannot be proposed as a standard care for patients with PM from primary breast cancer, the survival observed in our small series suggests that in highly selected patients with no extra peritoneal disease and in whom surgery can achieve adequate cytoreduction this combined procedure can offer patients a promising approach for long-term survival.

\section{Management of peritoneal carcinomatosis from small bowel adenocarcinoma}

Management of patients with PM from small bowel adenocarcinoma is unclear with literature reports episodic, even if PM is a frequent manifestation of small bowel carcinoma $[36,37]$. Typically, these tumors present after a significant delay in diagnosis for the vagueness of symptoms and imaging difficulty. Prognosis is poor with survival varying from 10 to 40 months. Marchettini and Sugarbaker [38] reported a median survival of 12 months with two of the patients treated with CRS and HIPEC with prolonged survival (57 and 59 months). Chua [39] reported seven cases treated with CRS and HIPEC (mitomycin C and EPIC with 5-FU), with a median disease-free survival of 12 months, and also reported a Kaplan-Meier analysis for a combined group of 19 patients treated with CRS and HIPEC with a median survival of 29 months. Shen et al. [40] reported a median survival of 45 months after treatment with CRS and HIPEC. Another large multiinstitutional experience is reported by the French Surgical Association [41], with a median survival for patients treated by CRS and HIPEC of 32 months. In the four patients treated in our Institution, mean survival was 31.2 months, with two patients alive disease-free at 43 and 22 months and two alive with disease at 33 (pulmonary metastases) and at 27 (abdominal recurrence) months. All the series reported show better results when compared to conventional treatments. Moreover, it has to be considered that CRS and HIPEC could represent the only valid surgical option for palliation in obstructed patients, in whom a simple surgical procedure aimed at bowel decompression is often impossible due to small bowel mesentery retraction or for the treatment of associated ascites.

\section{Management of peritoneal carcinomatosis from serous papillary (type II) uterine carcinoma (UPSC)}

Endometrial cancer is still the most common cancer of the female reproductive tract, and its treatment is surgical, alone or in combination with brachy and/or radiotherapy. Survival rates are approximately $90 \%$ at 5 years [42]. When compared to type I tumors, type II endometrial cancers are more likely to present or develop metastatic disease and have a less favorable diagnosis. In the presence of peritoneal metastases, the management becomes more complex and prognosis is poor, with a median survival not reaching 1 year. Bakrin [43] reported five patients with endometrial cancer treated by this combined modality, with a median survival of 19.4 months. Two patients experienced recurrent disease and died, while three patients are alive disease-free at 7, 23, and 39 months after treatment. Glehen [44] in a multi-institutional review of the French Surgical Association of 1290 patients with peritoneal metastases from various primary tumors reported the treatment of 17 patients with uterine adenocarcinoma and epidermoid carcinoma (4 patients), failing to give specific survival data for this specific group of patients. Delotte [42] in 2014 reported CRS and HIPEC in 13 patients with endometrial cancer. Five patients died of the disease and three are alive with disease at 14, 26, and 28 months, while four patients are alive disease-free at 1 , 60, 60, and 124 months. In our Institution, we treated eight patients with a diagnosis of type II UPSC with CRS and HIPEC. In four patients, we observed recurrent disease, and two of them died of the disease at 9 and 13 months, while two are alive with disease at 19 and 26 months. Four patients are alive disease-free at 9, 14, 26 , and 33 months. Treatment strategies for stage IV endometrial cancer remain controversial. Some reports highlight the histologic characteristics and extent of the disease as the main prognostic determinants, while others favor the effects of a more aggressive surgical cytoreduction. The long-term survival reported in these observational studies, higher when compared to those reported in literature with conventional treatments, seems to justify a more aggressive surgical attitude with the aim to leave the patients without residual visible disease.

\section{Management of peritoneal carcinomatosis from imatinib-resistant GISTosis}

Survival of patients with gastrointestinal stromal tumors (GIST) greatly improved with the clinical use of molecular-targeted therapies [45]. However, the prognosis of imatinib-resistant GIST disseminated to the peritoneum (spontaneously or during surgery) is poor. Accepted conventional treatments including palliative surgery, chemo, and/or radiotherapy are ineffective 
[46]. As with PM from other gastrointestinal or gynecologic epithelial tumors, a strong rationale favors aggressive locoregional treatment in these patients including peritonectomy procedures combined with HIPEC [47-48] even if its use is controversial due to the rarity of the condition and the few available published reports [49]. The results of our small series of three small bowel imatinibresistant GIST treated with CRS and HIPEC (two patients alive disease-free at 34 and 108 months, one patient died of disease at 38 months) are in line with similar reports (Table 2) and compare favorably with historical control groups justifying an effort to optimize treatment of the primary or recurrent GISTosis.

\section{Management of peritoneal carcinomatosis from other unconventional miscellaneous tumors}

The optimal management of patients with rare and unusual primary tumors metastatic to the abdominal cavity is a matter of intense debate. Systemic chemotherapy for PM improved but remains limited because of poor diffusion of the drugs into the peritoneum. This is why many authors [1,34, 35, 50-55] reported small observational series of patients with PM from various unconventional tumors treated by CRS and HIPEC (Table 2). This combined treatment modality has been used in peritoneal metastases from pancreatic, abdominal sarcomas, gallbladder, liver, cholangiocarcinoma, adrenal, urachal,

Table 2 CRS + HIPEC for PC from various primary tumors

\begin{tabular}{|c|c|c|c|c|c|c|}
\hline \multirow[t]{2}{*}{ Author (year) } & \multirow[t]{2}{*}{ Primary tumor } & \multirow[t]{2}{*}{ Number } & \multicolumn{4}{|l|}{ Overall survival } \\
\hline & & & Median (Months) & 1 year (\%) & 3 years (\%) & 5 years $(\%)$ \\
\hline Jacks (2005) [37] & Small bowel & 6 & 30 & - & - & - \\
\hline \multirow[t]{7}{*}{ Gusani (2008) [1] } & Unknown & 2 & 26.2 & - & 49 & - \\
\hline & Breast & 1 & & & & \\
\hline & GIST & 6 & & & & \\
\hline & Gallbladder & 1 & & & & \\
\hline & Liver & 1 & & & & \\
\hline & Adrenal & 1 & & & & \\
\hline & Esophagus & 1 & & & & \\
\hline \multirow[t]{8}{*}{ Shen (2009) [40] } & Unknown & 2 & 22.2 & 66 & 40 & 27 \\
\hline & Pancreas & 5 & & & & \\
\hline & GIST & 11 & & & & \\
\hline & Sarcoma & 10 & & & & \\
\hline & Gallbladder & 3 & & & & \\
\hline & Adrenal & 1 & & & & \\
\hline & Small bowel & 6 & & & & \\
\hline & Urachus & 5 & & & & \\
\hline Chua (2009) [3] & Small bowel & 7 & 25 & 57 & 20 & - \\
\hline Kerscher (2010) [50] & Small bowel & 3 & & - & - & - \\
\hline \multirow[t]{10}{*}{ Glehen (2010) [15] } & Unknown & 8 & 34 & 77 & 49 & 37 \\
\hline & Breast & 2 & & & & \\
\hline & GIST & 3 & & & & \\
\hline & Sarcoma & 28 & & & & \\
\hline & Liver & 2 & & & & \\
\hline & Adrenal & 3 & & & & \\
\hline & Urachus & 4 & & & & \\
\hline & Small bowel & 45 & & & & \\
\hline & Esophagus & 1 & & & & \\
\hline & Kidney & 2 & & & & \\
\hline Turrini (2012) [52] & Pancreas & 1 & - & - & - & - \\
\hline Randle (2013) [48] & Sarcoma & 10 & 21 & - & - & 43 \\
\hline
\end{tabular}

Review of the literature 
esophageal, and kidney tumors. In a multi-institutional review of the French Surgical Association on 1290 cases of PM from various primary tumors treated with CRS and HIPEC [41], the unconventional indications were 29. Mortality was $4.1 \%$ with a rate of major (grade 3 and 4) complications of $33 \%$, similar to those reported after other major surgical procedures. Obviously, the numbers are too small to draw any conclusion on survival figures for each specific primary tumor, but an overall median survival of 34 months, with a 5 -year disease-free survival of $22 \%$, compares favorably with survival figures reported in literature of palliative treatments for the same tumors.

\section{Conclusions}

We can conclude that CRS and HIPEC should not be excluded "a priori" for the treatment of peritoneal metastases from rare or unusual ("unconventional") primary tumors. This combined multimodality therapeutic approach, performed in selected patients in an experienced peritoneal surface malignancy center, is safe and has shown to provide not only a better palliation but also a survival benefit over conventional palliative treatments.

\section{Competing interests}

The authors declare that they have no competing interests.

\section{Authors' contributions}

MC designed the study; participated in acquisition, analysis, and interpretation of data; and drafted, wrote, and revised the manuscript. PS and DB participated in the draft of the manuscript and analysis and data interpretation and critically revised the manuscript. VM participated in data acquisition and interpretation and preparation and revision of the draft of the manuscript. SS and FA participated in data acquisition and analysis and interpretation and critically revised the manuscript. DM participated in the critical revision of the draft of the manuscript. BS participated in the critical revision of the draft of the revised manuscript after the reviewers' comments. ADG participated in data interpretation and critical revision of the manuscript. All authors gave final approval of the version to be published and agreed to be accountable for all aspects of the work.

\section{Author details}

'UOC Tecnologie Chirurgiche e Day Surgery, Dipartimento di Chirurgia "P. Valdoni", "Sapienza" Università di Roma, Rome, Italy. ${ }^{2}$ Dipartimento di Scienze Radioterapiche, Oncologiche ed Anatomopatologiche,

"Sapienza" Università di Roma, Rome, Italy. ${ }^{3}$ Via Bolzano 32, 00198 Rome, Italy.

Received: 2 March 2015 Accepted: 22 September 2015

Published online: 22 October 2015

\section{References}

1. Gusani NJ, Cho SW, Colovos C, Seo S, Franko J, Richard SD et al. Aggressive surgical management of peritoneal carcinomatosis with low mortality in a high volume tertiary center. Ann Surg Oncol. 2008;15:654-63.

2. Chu DZ, Lang NP, Thomson C, Osteen PK, Westbrook KC. Peritoneal carcinomatosis in non gynaecologic malignancies. A prospective study of prognostic factors. Cancer. 1989;63:364-7.

3. Chua TC, Robertson G, Liauw W, Farrell R, Yan TD, Morris DL. Intraoperative hyperthermic intraperitoneal chemotherapy after cytoreductive surgery in ovarian cancer peritoneal carcinomatosis: systematic review of current results. J Cancer Res Clin Oncol. 2009;135(12):1637-45.

4. Deraco M, Kusamura S, Virzi S, Puccio F, Macri A, Famulari C, et al. Cytoreductive surgery and hyperthermic intraperitoneal chemotherapy as upfront therapy for advanced epithelial ovarian cancer: multi-institutional phase-II trial. Gynecol Oncol. 2011;122(2):215-20.

5. Karlan B, Markmann MA, Eifel PJ. Ovarian cancer peritoneal carcinoma and fallopian tube carcinoma. In: De Vita Hellman R, editor. Cancer: principles and practice of oncology. 7th ed. Philadelphia: Lippincott, Williams and Wilkins; 2005.

6. Sadeghi B, Arvieux C, Glehen O, Beaujard AC, Rivoire M, Baulieux J, et al. Peritoneal carcinomatosis from non-gynecologic malignancies. Cancer. 2000;88(2):358-63.

7. Sugarbaker PH, Cunliffe WJ, Beliveau JF, de Bruin E, Graves T. Rationale for perioperative intraperitoneal chemotherapy as a surgical adjuvant for gastro-intestinal malignancies. Reg Cancer Treat. 1988;1:66-79.

8. Sugarbaker PH. Intraperitoneal chemotherapy and cytoreductive surgery for the prevention and treatment of peritoneal carcinomatosis and sarcomatosis. Semin Surg Oncol. 1988;14:254-61.

9. Chua T, Moran B, Sugarbaker PH. Early and long-term outcome on 2298 patients with psudomyxoma peritonei of appendiceal origin treated by a strategy of cytoreductive surgery and hyperthermic intraperitoneal chemotherapy. J Clin Oncol. 2012;30:2449-56.

10. Yan TD, Deraco M, Baratti D. Cytoreductive surgery and hyperthermic intraperitoneal chemotherapy for malignant peritoneal mesothelioma: multi institutional experience. J Clin Oncol. 2009;27:6237-42.

11. Di Giorgio A, Naticchioni E, Biacchi D, Sibio S, Accarpio F, Rocco M, et al. Cytoreductive surgery (peritonectomy procedures) combined with hyperthermic intraperitoneal chemotherapy (HIPEC) in the treatment of diffuse peritoneal carcinomatosis from ovarian cancer. Cancer. 2008;113:315-25.

12. Chang SJ, Bristow R, Tyu HS. Impact of complete cytoreduction leaving no gross residual disease associated with radical cytoreductive surgical procedures on survival in advanced ovarian cancer. Ann Surg Oncol. 2012;19:4059-67.

13. Helm WC. Current status and future directions of cytoreductive surgery and HIPEC in the treatment of ovarian cancer. Surg Oncol Clin N Am. 2012;21:645-63.

14. Yonemura Y, Kawamura T, Bandou E, Takahashi S, Sawa T, Matsuki N. Treatment of peritoneal dissemination from gastric cancer by peritonectomy and chemohyperthermic peritoneal perfusion. Br J Surg. 2005;92:370-5.

15. Glehen O, Gilly F, Arvieux C. Peritoneal carcinomatosis from gastric cancer: a multi institutional study of 159 patients treated by cytoreductive surgery combined with perioperative intraperitoneal chemotherapy. Ann Surg Oncol. 2010;17:2370-7.

16. Verwaal VJ, Van Ruth S, de Bree E, van Sloothen GW, van Tinteren H, Boot H, et al. Randomized trial of cytoreduction and hyperthermic intraperitoneal chemotherapy versus systemic chemotherapy and palliative surgery in patients with peritoneal carcinomatosis of colorectal cancer. J Clin Oncol. 2003;20:3737-43

17. Sammartino $P$, Sibio S, Biacchi D, Cardi M, Accarpio F, Mingazzini $P$, et al. Prevention of peritoneal metastases from colon cancer in high risk patients: preliminary results of surgery plus prophylactic HIPEC. Gastroenterol Res Pract. 2012;141585. doi:10.1155/2012/141585. Epub 2012 May 8.

18. Elias D, Lefevre JH, Chevalier J, Brouquet A, Marchal F, Classe JM, et al. Complete cytoreductive surgery plus intraperitoneal chemo-hyperthermia with oxaliplatin for peritoneal carcinomatosis of colorectal origin. J Clin Oncol. 2009;27:681-5.

19. Glehen O, Osinski D, Baujard AL, Gilly PN. Natural history of peritoneal carcinomatosis from non gynecological malignancies. Surg Oncol Clin N Am. 2003;12:729-39.

20. Carmignani CP, Sugarbaker TH, Bromley CN. Intraperitoneal cancer dissemination: mechanism of patterns of spread. Cancer Metastasis Rev. 2003;22:4105-72.

21. Sugarbaker PH. Cytoreductive surgery plus hyperthermic intraperitoneal chemotherapy for selected patients with peritoneal metastases from colorectal cancer. A new standard of care or an experimental approach? Gastroenterol Res Pract. 2012;309417: doi:10.1155/2012/309417.

22. du Bois A, Rochon J, Pfisterer J, Hoskins WJ. Variations in institutional infrastructure, physician specialization and experience, and outcome in ovarian cancer: a systematic review. Gynecol Oncol. 2009;112:422-36.

23. Elias D, David A, Sourrouille I, Honoré C, Goéré D, Dumon F, et al. Neuroendocrine carcinomas: optimal surgery of peritoneal metastasis (and associated intra-abdominal metastasis). Surgery. 2014;15(1):5-12.

24. Baratti D, Pennacchioli E, Kusamura S, Fiore M, Balestra MR, Colombo C, et al. Peritoneal sarcomatosis: is there a subset of patients who may benefit from 
cytoreductive surgery and hyperthermic intraperitoneal chemotherapy? Ann Surg Oncol. 2012;17:3220-8.

25. Kalliampust AA, Shukla NK, Deo SV, Yadav P, Mudaly D, Yadav R, et al. Updates on the multimodality management of desmoplastic small round cell tumors. J Surg Oncol. 2012;105:617-21.

26. World Health Organization. WHO handbook for reporting results of cancer treatments. Geneva 1979.

27. Jacquet $\mathrm{P}$, Sugarbaker PH. Clinical research methodologies in diagnosis and staging of patients with peritoneal carcinomatosis. Cancer Treat Res. 1996;82:359-74.

28. Sugarbaker PH, editor. Peritoneal carcinomatosis: principles and management. Boston: Kluwer; 1996.

29. United States Department of Public Health and Human Services, $\mathrm{NIH}, \mathrm{NCl}$ : Common Toxicity Criteria for Adverse Events (CTCAE). National Cancer Institute, June 2010. http://evs.nci.nih.gov/ftp1/CTCAE_Vers._4.03_2010-0614;_QuickReference_5x7.pdf

30. Cardi M, Sammartino P, Framarino ML, Biacchi D, Cortesi E, Sibio S, et al. Treatment of peritoneal carcinomatosis from breast cancer by maximal cytoreduction and HIPEC: a preliminary report on 5 cases. Breast. 2013;22:845-9.

31. Tuthill M, Pell R, Giuliani R, Lim A, Gudi M, Contractor KB, et al. Peritoneal disease in breast cancer: a specific entity with an extremely poor prognosis. Eur J Cancer. 2009:45:2146-9.

32. Stebbing J, Crane J, Gaya A. Breast cancer (metastatic). Clin Evid. 2006:2331-59.

33. Eitan R, Gemignani ML, Verkatraman ES, Barakat RR, Abu-Rustrum NR. Breast cancer metastatic to abdomen and pelvis. Role of surgical resection. Gynecol Oncol. 2003;90:397-401.

34. Abu-Rustum NR, Aghajanian CA, Venkatraman ES, Feroz F, Barakat RR. Metastatic breast carcinoma to the abdomen and pelvis. Gynecol Oncol. 1997;66:41-4.

35. Sheen-Chen SM, Liu YW, Sun CK, Lin SE, Eng HI, Huang WT, et al. Abdominal carcinomatosis attributed to metastatic breast carcinoma. Dig Dis Sci. 2008:53:3043-5.

36. Disario JA, Burt BW, Vargas H, McWhorter WP. Small bowel cancer: epidemiological and clinical characteristics from population-based registry. Am J Gastroenterol. 1994;89:699-701.

37. Jacks SP, Hundley JC, Shen P, Russel GB, Levine EA. Cytoreductive surgery and intraperitoneal hyperthermic chemotherapy for peritoneal carcinomatosis from small bowel adenocarcinoma. J Surg Oncol 2005;91:112-17.

38. Marchettini $\mathrm{P}$, Sugarbaker PH. Mucinous adenocarcinoma of the small bowel with peritoneal seeding. Case report and review of the literature. Eur J Surg Oncol. 2002;28:19-23.

39. Chua TC, Kohl JL, Yan TD, Liaw W, Morris DL. Cytoreductive surgery and perioperative intraperitoneal chemotherapy for peritoneal carcinomatosis from small bowel adenocarcinoma. J Surg Oncol. 2009;100:139-43.

40. Shen P, Stewart 4th JH, Levine EA. Cytoreductive surgery and intraperitoneal hyperthermic chemotherapy for peritoneal surface malignancy: non colorectal indications. Curr Probl Cancer. 2009;33:168-93.

41. Glehen O, Elias D, Gilly FN. Presentation du rapport de I'Association Francaise de Chirurgie. In: Elias D, Gilly EN, Glehen O, editors. Carcinoses péritoneales d'origine digestive et primitives. France: Arnette Walkers Kluwer; 2008;101-52.

42. Delotte J, Desantis M, Frigenza M, Quaranta D, Bongain A, Benchimol D, et al. Cytoreductive surgery with hyperthermic intraperitoneal chemotherapy for the treatment of endometrial cancer with peritoneal carcinomatosis. Eur J Obstet Gynocol Reprod Biol. 2014;172:111-4.

43. Bakrin N, Cotte E, Sayag-Beaugard A, Raudrand N, Isaac S, Mohamed F, et al. Cytoreductive surgery with hyperthermic intraperitoneal chemotherapy for the treatment of recurrent endometrial carcinoma confined to the peritoneal cavity. Int J Gynecol Cancer. 2010;20:809-14.

44. Glehen O, Gilly F, Boutitie F, Bereder JM, Quenet F, Sideris L, et al. Toward curative treatment of peritoneal carcinomatosis from non ovarian origin by cytoreductive surgery combined with perioperative intraperitoneal chemotherapy. Cancer. 2010;16:5608-18.

45. Demetri GD, von Mehren $M$, Blanck CD, Van den Abbeele AD, Eisenberg $B$, Roberts PJ, et al. Efficacy and safety of imatinib mesylate in advanced gastrointestinal stromal tumors. N Engl J Med. 2002;347:472-80.

46. Bilimoria MM, Holz DJ, Mirza NQ, Feig BV, Pisters BW, Patel S, et al. Tumor volume as a prognostic factor for sarcomatosis. Cancer. 2002;94:2441-6.
47. Glehen O, Sugarbaker PH Eds. Special issue on management of peritoneal carcinomatosis from colorectal and appendiceal malignancies. Cancer $\mathrm{J}$. 2009;15:216-24.

48. Randle RW, Swett KR, Shen P. Stewart JH, Levine EA, Vatanopoulos Kl. Cytoreductive surgery with hyperthermic intraperitoneal chemotherapy in peritoneal sarcomatosis. Am Surg 2013;6:620-4.

49. Rossi CR, Casali PG, Kusamura S, Baratti D, Deraco M. The consensus statement on the locoregional treatment of abdominal sarcomatosis. J Surg Oncol. 2008;94:291-4.

50. Kerscher AG, Mallalieu J, Pitroff A, Kerscher F, Esquivel J. Morbidity and mortality of 109 consecutive cytoreductive procedures with hyperthermic intraperitoneal chemotherapy (HIPEC) performed at a community hospital. World J Surg. 2010;34:62-9.

51. Levine EA, Stewart JH, Shin P, Russell GB, Loggie BL, Votanopoulos Kl. Intraperitoneal chemotherapy from peritoneal surface malignancy: experience with 1000 patients. J Am Coll Surg. 2014;218:573-87.

52. Turrini O, Lambaudie E, Faucher M, Viret F, Blache JL, Houvenhaegel G, et al. Initial experience with hyperthermic intraperitoneal chemotherapy. Arch Surg. 2012;147:919-23.

53. Yoon W, Alame A, Beni R. Peritoneal surface disease severity score as a predictor of resectability in the treatment of peritoneal surface malignancies. Am J Surg. 2014;207:403-7.

54. Votanopoulos KI, Newman NA, Russel G, Ihemelandu C, Shen P, Stewart JH, et al. Outcomes of cytoreductive surgery (CRS) with hyperthermic intraperitoneal chemotherapy (HIPEC) in patients older than 70 years: survival benefits at considerable morbidity and mortality. Ann Surg Oncol. 2013;20:3497-503.

55. Sun Y, Chen P, Stewart JH, Russell GB, Levine EA. Cytoreductive surgery and hyperthermic intraperitoneal chemotherapy for peritoneal carcinomatosis from small bowel adenocarcinoma. Am Surg. 2013;79:644-8.

\section{Submit your next manuscript to BioMed Central and take full advantage of:}

- Convenient online submission

- Thorough peer review

- No space constraints or color figure charges

- Immediate publication on acceptance

- Inclusion in PubMed, CAS, Scopus and Google Scholar

- Research which is freely available for redistribution

Submit your manuscript at www.biomedcentral.com/submit
C) Biomed Central 